\title{
Introduction: Language attrition as a complex, non-linear development
}

Monika S. Schmid, Barbara Köpke, Kees de Bot

There is a long-standing debate in bilingualism studies on whether or not there is a qualitative difference in acquisitional processes and ultimate knowledge between languages acquired from birth or in early childhood and languages learned later in life. Whether or not there actually is a maturationally conditioned change around puberty which impacts on these matters remains an open question. However, one thing can be said with certainty: the language that was used in parent-child interactions, that is linked with the earliest memories, and that was acquired at the same time that other important early cognitive developments took place, is unique in that it is irrevocably tied into fundamental aspects of a speaker's personality and memory in complex ways.

This is illustrated poignantly in the recollections of a German-Jewish migrant who was sent to England, alone, in 1939 when she was thirteen years old, and who later learned that her parents and all other family members who had stayed behind had perished in the concentration camps. For this speaker, the German language came to represent all of the terrors and losses that she had suffered, and when she first visited Germany again after the war, she felt that she could not tolerate being exposed to the language, that hearing it spoken caused her physical discomfort. This repulsion remained with her all her life - with one exception: when she herself became a mother and later a grandmother, she talked and sang to the infants in the language that her own parents had used with her when she was that age.

This account illustrates the vast and sometimes conflicting range of symbolic functions and associations that the native language (L1) can have for an individual. For speakers who change their linguistic environment later in life through migration, such functions can interact in complex ways and impact on language choice, linguistic behaviour and language development. We know of such effects from the process of second language (L2) acquisition: positive attitudes towards the L2 speech community, or to individual speakers, can enhance the learning experience and lead to higher proficiency levels (e.g. Gardner 2010). Attitudes can thus interact with input in shaping the growth of language knowledge. Where L1 attrition is concerned, it is therefore important to determine which of the external aspects that can govern language acquisition and use have the potential to shape and predict the outcome of the process of language maintenance, change or loss.

As Roger Andersen put it thirty years ago, "[1]anguage attrition is a special case of variation in the acquisition and use of a language or languages and can best be studied, 
described, documented, explained, and understood within a framework that includes all other phenomena of language acquisition and use.” (Andersen 1982: 86). This desideratum, formulated at the very onset of attrition studies and long before Dynamic Systems Theory (DST) had been applied to language, has lost nothing of its relevance thirty years on and fits in perfectly with the DST framework, which guides the contributions to the present collection. And yet, what does it mean to include 'all other phenomena' of language acquisition and use? To what extent is it even possible?

Several groups of factors have been investigated in this respect. Firstly, it has long been assumed that language attrition may depend on personal background factors such as the age at onset $(\mathrm{AaO})$ or the length of residence (LOR). Secondly, input and exposure - the amount of use a speaker makes of her L1 - are often invoked as determining factors. And lastly, personal attitudes and experiences are generally taken to be factors which may impact on L1 maintenance or attrition. These predictions, however, have proven very difficult to verify: attrition does not seem to progress linearly over longer time-periods (e.g. de Bot \& Clyne 1994, Schmid \& Dusseldorp 2010), nor is it associated in any straightforward way with the frequency of L1 exposure or use across a variety of contexts (Schmid 2007, Schmid \& Dusseldorp 2010). On the other hand, non-linear interactions between factors such as time and use or age have been found demonstrating that the impact of length of residence on attrition is stronger for migrants who have very little contact with their L1 (de Bot, Gommans \& Rossing 1991, Soesman 1997, but see Schmid 2011) and that the decline in performance on some tasks which is typically found among elderly speakers appears to be somewhat attenuated for attriters (Schmid \& Keijzer 2009).

The only direct comparison so far of language use and language attitude patterns on the one hand, and crosslinguistic influence on the other, among both attriters and L2 learners is the investigation of perceived foreign accent among 40 long-term L1 attriters in the Netherlands $(n=20)$ and Canada $(n=20)$ and 40 advanced L2 learners of German with Dutch $(n=20)$ and English(n=20) presented by Hopp and Schmid (forthc.). This study reveals first of all that, while both the attriter and the L2 population comprises a subset of speakers who are perceived to be native-like as well as a number of individuals who are not, the proportion of individuals who are indistinguishable from the predominantly monolingual native controls is larger among the attriters than among the L2ers. In other words, among long-term, proficient routine bilinguals, traffic from L2 to L1 (Schmid \& Köpke, 2007) appears to be less pronounced than traffic vice versa. In an attempt to account for interindividual variation, Hopp and Schmid investigate self-reported language use across a range of domains. This 
analysis demonstrates that success in the acquisition of L2 pronunciation can be predicted to some extent by the degree of use of this language in the most intensive and sustained communicative settings, namely language use with the partner. For the attriters, no such correlations could be established: the use of German across a variety of contexts, ranging from informal communication through formal speech to inner language functions, did not appear to affect the foreign accent ratings in any way.

These findings do seem to suggest that the unique status of the language which is learned in childhood impacts strongly on choices and developments later on - more so than is the case for later-learned languages. A complex, unpredictable and dynamic interaction process between "all other phenomena of language acquisition and use" (Andersen 1982: 86) does therefore apparently characterize language development under attrition. In order to adequately capture and describe this interaction, more studies are needed. These should either be in the form of microanalytic longitudinal case-studies, which can describe and assess the changing impact of each predictor across time, or very large-scale investigations that will allow to statistically assess the combined and interactive impact of a variety of predictors.

The only external factor that has been shown to have an indisputable and comparatively straightforward impact on language attrition is age at onset. There is a large amount of cumulative evidence to suggest that L1 maintenance and attrition differ quite radically between speakers for whom full exposure to the L1 ceased before and after puberty (see e.g. the overviews in Bylund 2009 and Montrul 2008). Among younger populations, the lexicon, grammar and phonology of the native language can be significantly restructured from the native norm, while older migrants have never been shown to be affected by structural loss of any kind (see Schmid forthc.). An example in point are the investigations by Schmitt (2010) and Schmid (2002): Schmitt investigates five Russian-English bilinguals who came to the US, in the company of their parents, at between 10 and 12 years of age and were young adults at the time of the study. Her analysis of case marking in free speech from these speakers reveals that, while the nominative case is used accurately in $96 \%$ of all obligatory contexts (ie. sentence positions in the data which require a particular case in Standard Russian), oblique cases (such as genitive, dative or accusative) are only used in a target-like fashion around two thirds of the time. In aprticular, the Russian instrumentative case appears to be affected, as it is used accurately in about one third of all obligatory contexts.

Similarly, Schmid's 2002 study invokes 35 German-English bilinguals, who were 11 years or older at the time of migration to English-speaking countries. Among other things, she also investigates errors in case marking, which in this study are related to total number of 
words, not obligatory contexts. For the overall population, case marking errors do not appear to be associated with age at migration (Schmid 2002: 175). However, a closer look at the youngest migrants (those who were between 11 and 14 years at migration) reveals a sharp drop-off in the error rate across this age range (see Fig. 1).

/ insert Fig. 1 here /

The recurrent finding that migrants' proficiency in the L1 varies dramatically, according to whether their arrival in the new linguistic environment took place before or after the onset of puberty has important methodological implications. Any study wanting to investigate this contrast will be faced with the challenge of designing tasks that are not too simple for the attriters (who typically retain a proficiency that differs only minimally from that of monolingual native speakers) but at the same time not too difficult for the incomplete learners (who have often been shown to have experienced wholesale restructurings and simplifications of grammatical categories). This implies that most formal tasks will not be suitable to test the differential levels of language loss across the full range of age at onset, since they will either produce a ceiling effect (that is, a lack of variability) among the older migrants or be too difficult to complete for the younger ones. The best-suited data for the analysis of language attrition and incomplete acquisition, in particular in overarching studies where the range of age at onset encompasses both pre- and post-puberty migrants, may therefore be free spoken data, which allow every speaker to employ the full range of her language knowledge.

Free data have a second considerable advantage over formal, elicited tasks: the latter are typically designed to measure only one aspect of language knowledge, such as lexical access (e.g. Picture Naming Task, Verbal Fluency Task), knowledge of grammatical rules (Grammaticality or Truth Value Judgment Task) etc. However, it has been demonstrated that for postpuberty migrants, attrition phenomena do not affect underlying, structural aspects of the language but are the outcome of online problems in the integration of linguistic knowledge on all cognitive levels of language production and processing (Schmid 2009; forthc.). Tasks such as the ones mentioned above, which allow the speaker to focus all her attention on one aspect of language, therefore may not reliably detect attrition effects.

In this respect also, DST might provide an important and valuable framework and allow insights into the attritional process which go beyond the more traditional investigations. With very few exceptions, research on attrition (but also on bilingualism at large) has always focussed on individual grammatical features, designing and employing tasks that allow 
tapping into one phenomenon at a time (even studies which consider more than one grammatical feature usually investigate each in isolation). Such an approach makes sense if the researcher is interested in answering questions about underlying, structural knowledge of such features. A speaker who has not internalized, for example, the rules of an L2 case system will be unable to complete any task which requires her to draw on this knowledge, whether this be a grammaticality judgment, a sentence completion or a free speech task. However, relatively recent models of bilingual knowledge point out that deviant performance on such tasks may occur despite target-like underlying knowledge. This is evident from the fact that even native speakers usually do not achieve perfect scores on most tasks and aggravated in L2 learners who are faced with the added complexities of managing two or more language systems, as pointed out for example by Prévost and White (2000) in their study on late L2 learners of French and German. On the other hand, researchers have questioned the nature of the knowledge underlying target-like behaviour of bilinguals, arguing that they may take recourse to non-grammatical compensatory strategies in the absence of truly native-like structural knowledge (Hawkins \& Tsimpli 2008). It has also been suggested that advanced L2 learners may be able to perform to native levels "on certain well-defined tasks or within certain restricted domains" (Long 2005:289) but fail to be able to replicate this performance under the demands of real-life language use.

If we accept the proposition that language users may perform in a target-like fashion in the absence of underlying linguistic knowledge that is identical to the resources which monolingual native speakers have (on the basis of compensatory strategies, under certain task demands), and that, on the other hand, they may use language in an apparently deviant way even though they do possess this knowledge (due to competing demands and cross-linguistic interference), we have to question the tasks which we use in order to obtain our data, and reevaluate our evidence. To take this argument to its extremes, it may be possible to teach someone who is otherwise unfamiliar with a given language the mechanisms underlying a certain agreement rule, and that person would then be able to distinguish correct and incorrect applications of this rule. On the other hand, psycholinguistic research has shown that even monolingual native speakers may behave like beginners when the cognitive load of a task is increased through time pressure and higher structural complexity (see for example, at the level of written production Chanquoy \& Negro, 1996 or Fayol, Largy \& Lemaire, 1994). Recently, it has been demonstrated that monolingual native speakers may even become indistinguishable from L2 learners when put under pressure: Hopp (2010) required both natives and non-natives to make grammaticality judgments of sentences displayed on a 
computer screen one word at a time (rapid serial visual presentation (RSVP)). In the 'normal' mode of presentation, where each word was presented for $250 \mathrm{~ms}$ plus $17 \mathrm{~ms}$ per letter, the native speakers outperformed the L2ers. Hopp then successively shortened the base interval of $250 \mathrm{~ms}$, and found that at the fastest rate of presentation ( $71 \mathrm{~ms}$ plus $17 \mathrm{~ms}$ per letter), the natives became indistinguishable from the L2ers.

It may thus be possible to gain similar insights into the attritional process by exposing speakers to tasks which force them to apply more and more of their limited cognitive resources. This should reveal the more vulnerable areas of their linguistic knowledge on the basis of the "something's gotta give" principle. Many of the experiments that are most popular in attrition research, however, such as grammaticality or truth value judgment tasks (as used by e.g. Ribbert \& Kuiken, 2010; Kim, Montrul \& Yoon, 2010), naming tasks (e.g. Yilmaz, forthc.) or inflectional tasks (Keijzer, 2007) make no such demands on their participants, allowing them to focus their entire attention on one aspect of language production or processing.

Arguably, however, the best and most natural way of ensuring that a participant applies her cognitive resources to all aspects of the message is to simply make her do what human beings normally do with language: speak. Natural speech requires the rapid online integration and processing of information from many different levels. In native speakers and advanced L2ers, this processing is largely automatized and thus incurs little or no cognitive cost or delays. Speakers who are less advanced or have not used the language for a long time, however, encounter difficulties with some structures. In such cases, trade-off effects between phenomena concerning complexity, accuracy and fluency may be observed, in that speakers may:

- $\quad$ use the structure incorrectly (accuracy)

- $\quad$ avoid the use of such structures altogether (complexity). This may be possible for some areas of grammar (e.g. subordinate clauses, plural) but not for others (e.g. tense, case, gender, phonology)

- $\quad$ expend extra effort on the structure, leading to errors on other structures (accuracy)

- $\quad$ expend extra effort on the structure, leading to a delay in speech production (fluency)

- expend extra effort on the structure, leading to a decrease in complexity in the rest of the utterance (complexity) 
In order to fully capture a speaker's proficiency, all utterances therefore have to be investigated for complexity, accuracy and fluency. This procedure allows investigating what areas of grammar or phonology a speaker finds difficult, and how these difficulties impact on other parts of the message. Consider the following example (which stems from an interview with the German-Jewish speaker mentioned above, the symbol \# represents a pause):
(1)a ja ich erinner mich an \# manche Sachen
yes I remember myself to some things
"Yes, I do recall some things,"
(1)b

$\begin{array}{lllllllllllll}\text { ahm } & \text { nicht } & \text { sehr } & \text { sehr } & \text { viel } & \text { aber } & \# & * \text { manches } & \text { kann } & \text { ich } & \text { mich } & \text { noch } & \text { erinnern. } \\ \text { ah } & \text { not } & \text { very } & \text { very } & \text { much } & \text { but } & & \text { some things } & \text { can } & \text { I } & \text { myself } & \text { still } & \text { remember. }\end{array}$
"ah not very very much but I can still recall a few."

The first part of this sentence is a simple main clause with SVO word order. There are no disfluencies except one pause, and no errors. The second sentence is more complex, with a co-ordinated subclause, object-fronting triggering S-V inversion and discontinuous word order involving a modal auxiliary (kann) and an infinitival component (erinnern), which frame the subject, reflexive pronoun and temporal adverbial. In this sentence, there are more disfluencies (a filled pause, a repetition and an empty pause) and also an error (omission of the preposition an). This error cannot be taken as evidence that the speaker no longer knows that the German expression sich an etwas erinnern (lit. to remember oneself to something, 'to remember something') takes the preposition an, since she used the same construction including the preposition in the previous utterance. We are therefore probably dealing with a case of cognitive overload - the increased complexity of the sentence prevents her from uttering it in a completely target-like fashion.

Micro-investigations of this type, which do not simply average factors such as fluency, lexical diversity, sentence patterns or error distribution across all of the data produced by one speaker or by a group of speakers, have been proposed as one way forward in Dynamic Systems Theory. Analyses of such data by means of sophisticated statistical methods have shown how development in L2 acquisition can be explained in terms of the interaction of all of these features under constraints of structural order and resource limitations (e.g. Caspi, 2010). 
In summary, we might elaborate the quotation from Roger Andersen with which we started this overview: Language attrition is a complex and dynamic process of change, development and cross-linguistic interaction. It is affected and governed by a non-linear interaction of extralinguistic factors. Overall developments and ad-hoc modifications due to cross-linguistic influence are not confined to one linguistic feature or level, but have ramifications across the entire message and system. As such, it can best be studied, described, documented, explained, and understood within a framework that includes all other phenomena of language acquisition and use. Dynamic Systems Theory is such a framework.

\section{References:}

Andersen, R. W. (1982). Determining the linguistic attributes of language attrition. In R. D. Lambert \& B. F. Freed (Eds.), The loss of language skills (pp. 83-118). Rowley, MA: Newbury House.

Bot, K. de \& Clyne, M. (1994). A 16-year longitudinal study of language attrition in Dutch immigrants in Australia. Journal of Multilingual and Multicultural Development 15 (1): $17-18$.

Bot, K. de, Gommans, P. \& Rossing, C. (1991). L1 Loss in an L2 Environment: Dutch Immigrants in France. In H.W. Seliger \& R. M. Vago (Eds), First Language Attrition (pp. 87-98). Cambridge University Press.

Bylund, E. S. (2009). Maturational constraints and first language attrition. Language Learning, 59(3), 687-715.

Caspi, T. (2010). A Dynamic Perspective on Second Language Development. $\mathrm{PhD}$ dissertation, University of Groningen.

Chanquoy, L. \& Negro, I. (1996). Subject-verb agreement errors in written production : study in French children and adults. Journal of Psycholinguistic Research, 25, 553-570.

Fayol, M., Largy, P. \& Lemaire, P. (1994). Cognitive overload and orthographic errors: When cognitive overload enhances subject-verb agreement errors: A study in French written language. Quarterly Journal of Experimental Psychology, 47, 437-464.

Gardner, R. C. (2010). Motivation and Second Language Acquisition. New York et al.: Peter Lang.

Hawkins, R. \& Tsimpli, I. (2009). Explaining target- and non-target performance in the acquisition of Gender concord by L2 speakers. Paper presented at ISB7, Utrecht, July 2009. 
Hopp, H. \& Schmid, M. S. forthc. Perceived foreign accent in L1 attrition and L2 acquisition: the impact of age of acquisition and bilingualism. To appear in Applied Psycholinguistics.

Keijzer, M. (2007). First Language Attrition: an investigation of Jakobson's regression hypothesis. PhD dissertation, Vrije Universiteit Amsterdam.

Kim, J-H., Montrul, S. and Yoon, J. (2010). Dominant language influence in acquisition and attrition of binding: Interpretation of the Korean reflexive caki. Bilingualism: Language and Cognition, 13, 73-84 .

Long, M. (2005). Problems with supposed counter-evidence to the Critical Period Hypothesis. International Review of Applied Linguistics 43(4), 287-317.

Montrul, S. A. (2008). Incomplete Acquisition in Bilingualism. Amsterdam/Philadelphia: John Benjamins.

Prévost, P. \& White, L. (2000). Missing surface inflection or impairment in second language acquisition? Evidence from tense and agreement. Second Language Research, 16(2), $103-133$.

Ribbert, A. \& Kuiken, F. (2010). L2-induced changes in the L1 of Germans living in the Netherlands. Bilingualism: Language and Cognition 13(1), 41-48.

Schmid, M. S. (2002). First Language Attrition, Use and Maintenance: The case of German Jews in Anglophone countries. Amsterdam: John Benjamins.

Schmid, M. S. (2007). The role of L1 use for L1 attrition. In B. Köpke, M. S. Schmid, M Keijzer \& S. Dostert. (Eds.), Language Attrition: Theoretical perspectives, (pp. 135153). Amsterdam/Philadelphia: John Benjamins.

Schmid, M. S. (2009). On L1 attrition and the linguistic system. EUROSLA Yearbook, 9, 212 244.

Schmid, M. S. (2011). Contact x time: External factors and variability in L1 attrition. M. S. Schmid \& W. Lowie. (Eds.), Modeling Bilingualism: from structure to chaos. In honour of Kees de Bot, (pp. 155-176). Amsterdam/Philadelphia: John Benjamins.

Schmid, M. S. forthc. L1 attrition. To appear in: Linguistic Approaches to Bilingualism.

Schmid, M. S. and Dusseldorp, E. (2010). Quantitative analyses in a multivariate study of language attrition. Second Language Research, 26 (1), 125-160.

Schmid, M. S. \& Keijzer, M. 2009. First language attrition and reversion among older migrants. International Journal of the Sociology of Language, 200, 83-101 
Schmid, M. S. \& Köpke, B. (2007). Bilingualism and attrition. B. Köpke, M. S. Schmid, M Keijzer \& S. Dostert. (Eds.), Language Attrition: Theoretical perspectives, (pp. 1-8). Amsterdam/Philadelphia: John Benjamins.

Schmitt, E. (2010). When boundaries are crossed: Evaluating language attrition data from two perspectives. Bilingualism: Language and Cognition, 13(1), 63-72.

Soesman, A. (1997). An experimental study on native language attrition in Dutch adult immigrants in Israel. In J. Klatter-Folmer and S. Kroon (eds), Dutch Overseas: Studies in Maintenance and Loss of Dutch as an Immigrant Language, (pp. 181-194). Tilburg:

Tilburg University Press.

Yilmaz, G. forthc. Lexical diversity in attrition. 